\title{
STUDIES IN CUSHING'S SYNDROME. III. URINARY 17-KETOSTEROIDS IN PATIENTS WITH BILATERAL ADRENAL CORTICAL HYPERPLASIA *
}

\author{
By JOSEPH W. JAILER, RAYMOND VANDE WIELE, NICHOLAS P. CHRISTY $\dagger$ \\ AND SEYMOUR LIEBERMAN \\ (From the Departments of Medicine and Obstetrics and Gynecology, the College of Physicians \\ and Surgeons, Columbia University, and the Presbyterian Hospital, \\ New York, N. Y.)
}

(Submitted for publication August 22, 1958; accepted October 9, 1958)

There are several reports in the literature concerning urinary 17 -ketosteroids in patients with Cushing's syndrome associated with bilateral adrenal cortical hyperplasia (1-7). In most of the published studies, identification of the individual 17 -ketosteroids was incomplete, so that the sum of detailed information available is limited. With the development of improved techniques for steroid fractionation and identification, a re-evaluation of the problem seemed indicated. The present investigation was therefore undertaken with a twofold purpose: 1) to make a detailed study of the urinary 17-ketosteroids in patients with this form of Cushing's syndrome; and 2) to determine whether or not the administration of corticotropin to normal subjects was capable of reproducing the excretory pattern of 17-ketosteroids found in Cushing's syndrome with bilateral adrenal cortical hyperplasia. It seemed likely that the data resulting from such studies might provide useful information bearing upon the pathogenesis of this disorder.

\section{MATERIALS AND METHODS}

Patients with Cushing's syndrome and bilateral adrenal cortical hyperplasia. Seven patients having the typical clinical and laboratory features of Cushing's syndrome served as the subjects for the study. Pertinent data obtained from these patients are presented in Table $I$. The absence of adrenal cortical tumor was proved in six of the seven patients by operation (bilateral total or subtotal adrenalectomy). In the seventh patient (Bon.), intravenous pyelography and retroperitoneal insufflation of air gave no evidence of a suprarenal mass. Two of the subjects (Bon. and Fan.) were studied before and during the administration of corticotropin. Bon. received a single intravenous infusion of lyophilized adrenocorticotropic hormone (ACTH), 25 I.U., over an eight

* Aided by grants (A-195 and A-1083) from the National Institutes of Health, United States Public Health Service.

† John and Mary R. Markle Scholar in Medical Science. hour period. Fan. received corticotropin gel, 40 I.U. intramuscularly twice daily for three days.

Subjects without adrenal cortical disease. Normal values for the individual 17 -ketosteroids were derived from a study of 8 normal males (age range, 21 to 35) and 13 normal females (age range, 20 to 31 ). These subjects were presumably healthy laboratory workers who were carrying on their usual activities. The average values are summarized in Table II. The data are to be published in detail elsewhere.

Two normal females aged 26 and 27 years were studied before and during three day periods of corticotropin administration (ACTH gel, 40 I.U. intramuscularly, twice a day). In addition, studies were carried out in two patients who had been treated with corticotropin for prolonged periods. Patient M.S., a 41 year old white female with bronchial asthma, had received intramuscular doses of 5 to 20 I.U. (lyophilized and gel preparations) with a frequency ranging from once a day to once a week for three years. Patient E.U., a 58 year old white male with rheumatoid arthritis, had been given intramuscular corticotropin (lyophilized and gel) in doses of 2 to 20 I.U. daily or every other day for two years.

Methods. Twenty-four hour urine specimens were collected for periods of one to seven days. If not proc-

TABLE I Clinical and laboratory data of patients with Cushing's
syndrome associated with bilateral adrenal cortical hyperplasia

\begin{tabular}{|c|c|c|c|c|c|c|}
\hline \multirow[b]{2}{*}{ Name } & \multirow[b]{2}{*}{ Age } & \multirow[b]{2}{*}{ Sex } & \multirow{2}{*}{$\begin{array}{c}\text { "Crude" } \\
\text { 17-ks.* } \\
\text { (8) }\end{array}$} & \multirow[b]{2}{*}{$\begin{array}{c}\text { Urine } \\
\text { 17-OH-CS† }\end{array}$} & \multicolumn{2}{|c|}{$\begin{array}{c}\text { Plasma 17-OH-CS } \\
(17,42,43)\end{array}$} \\
\hline & & & & & $\begin{array}{l}\text { Before } \\
\text { ACTH }\end{array}$ & $\begin{array}{l}\text { After } \\
\text { ACTH }\end{array}$ \\
\hline & yrs. & & mg. $/ 24$ hrs. & mg./24 hrs. & \multicolumn{2}{|c|}{$\mu g . / 100 \mathrm{ml}$. } \\
\hline Arp. & 21 & & 23.3 & 20.3 & 29 & 49 \\
\hline Cor. & 23 & $\mathrm{~F}$ & 11.2 & 9.2 & 35 & 82 \\
\hline Par. & 29 & M & 18.1 & 11.8 & 37 & 61 \\
\hline See. & 33 & $\mathbf{F}$ & 26.6 & 8.5 & 27 & 100 \\
\hline Fan. & 39 & $\mathbf{F}$ & 42.6 & 28.8 & 28 & 81 \\
\hline Bon. & 46 & M & 22.8 & 12.5 & 22 & 63 \\
\hline Gol. & 53 & $\mathbf{F}$ & 19.7 & 16.6 & 48 & 120 \\
\hline \multirow{2}{*}{\multicolumn{3}{|c|}{ Range of normal }} & & & & \\
\hline & & & $8-20$ & $3-9$ & $4-23$ & $35-55$ \\
\hline
\end{tabular}

* 17-Ketosteroids.

$\dagger$ Porter-Silber chromogen after beta-glucuronidase hydrolysis. 


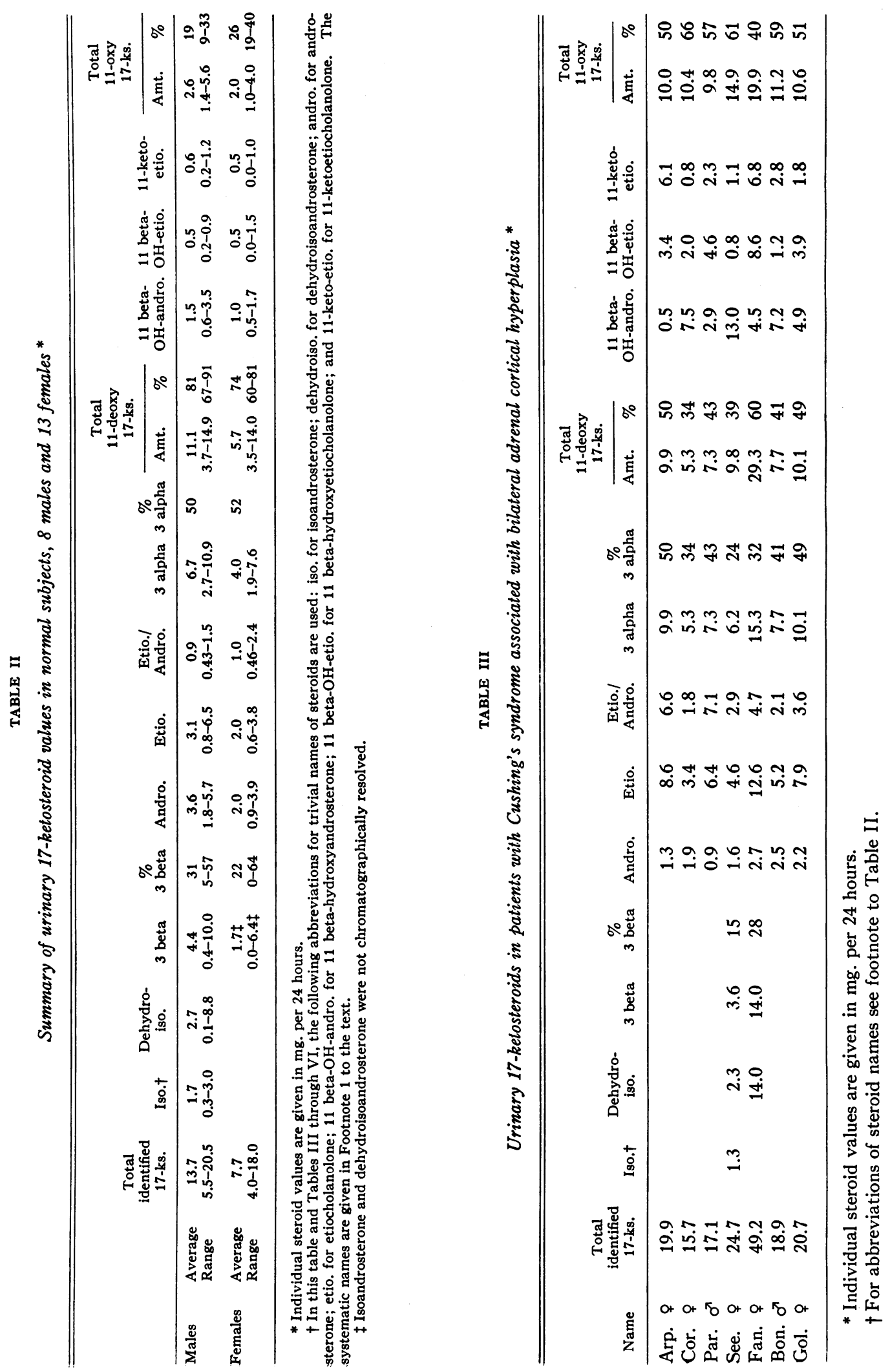


essed immediately, the specimens were refrigerated without preservative.

Total urinary 17-ketosteroids (per 24 hours) were estimated by the colorimetric method of Holtorff and Koch (8). For the isolation of the individual 17-ketosteroids, the urine was subjected to enzymatic hydrolysis (betaglucuronidase). This was followed by cold, then hot, acid hydrolysis (9). Extracts were chromatographed on alumina according to the technique of Lakshmanan and Lieberman (10). All Zimmermann values were corrected for differences in chromogenicity of the various steroids (11). In every instance, steroids in the chromatographic peaks were identified by infrared spectroscopy.

With this method of fractionation (10) it is not possible to separate chromatographically dehydroisoandrosterone from isoandrosterone, androsterone from $\Delta^{\vartheta}$-androstenolone, or etiocholanolone from $\Delta^{*}$-etiocholenolone. ${ }^{1}$ Quantitation of the individual components of these three binary mixtures was performed by the sulfuric acid chromogen method of Bitman, Rosselet, Reddy and Lieberman (12). Since the $\Delta^{\circ}$-unsaturated compounds are probably artifacts of dehydration resulting from hot acid hydrolysis of the 11 beta-hydroxy 17-ketosteroids (13), the quantities of $\Delta^{\circ}$-androstenolone and $\Delta^{\circ}$-etiocholenolone were added to the values for 11 beta-hydroxyandrosterone and to 11 beta-hydroxyetiocholanolone, respectively. The presence of the $\Delta^{\theta}$ steroids and of isoandrosterone was established in each instance by infrared spectroscopy, as well as by the sulfuric acid chromogen method (12).

\section{RESULTS}

\section{Cushing's syndrome with bilateral adrenal cor- tical hyperplasia}

Values for the individual 17-ketosteroids in the seven patients with bilateral adrenal cortical hy-

1 The following trivial names for $\mathrm{C} 19$ steroids are used in this paper: androsterone for $3 \alpha$-hydroxyandrostan-17one; etiocholanolone for $3 \alpha$-hydroxyetiocholan-17-one; dehydroisoandrosterone for $3 \beta$-hydroxy- $\Delta^{5}$-androsten-17one; isoandrosterone for $3 \beta$-hydroxyandrostan-17-one; $\Delta^{*}$-androstenolone for $3 \alpha$-hydroxy- $\Delta^{2},{ }^{11}$-androsten-17-one; $\Delta^{\theta}$-etiocholenolone for $3 \alpha$-hydroxy- $\Delta^{0,11}$-etiocholen-17-one; $11 \beta$-hydroxyetiocholanolone for $3 \alpha, 11 \beta$-dihydroxyetiocholan-17-one; $11 \beta$-hydroxyandrosterone for $3 \alpha, 11 \beta$-dihydroxyandrostan-17-one; 11-ketoetiocholanolone for $3 \alpha$ hydroxyetiocholane-11,17-dione; and 11-ketoandrosterone for $3 \alpha$-hydroxyandrostane-11,17-dione. For certain C21 steroids, the following trivial names are employed: hydrocortisone for $11 \beta, 17 \alpha, 21$-trihydroxy- $\Delta^{4}$-pregnene-3,20dione; Substance $S$ for 17 $\alpha, 21$-dihydroxy- $\Delta^{4}$-pregnene-

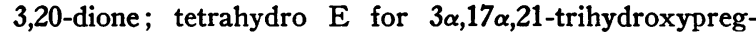
nane-11,20-dione; tetrahydro $F$ for $3 \alpha, 11 \beta, 17 \alpha, 21$-tetrahydroxypregnan-20-one; tetrahydro $S$ for $3 \alpha, 17 \alpha, 21$-trihydroxypregnan-20-one; $17 \alpha$-hydroxyprogesterone for $17 \alpha$ hydroxy- $\Delta^{4}$-pregnene-3,20-dione; $17 \alpha$-hydroxypregnanolone for $3 \alpha, 17 \alpha$-dihydroxypregnan-20-one; and pregnanetriol for pregnane-3 $\alpha, 17 \alpha, 20 \alpha$-triol, perplasia are shown in Table III. The total quantity of identified 17-ketosteroids was moderately increased in three subjects (Arp., See., Gol.), markedly increased in one (Fan.), and normal in the remaining three (Cor., Par. and Bon.).

Analysis of urinary 17-ketosteroids revealed three findings of note. 1) When compared with the normal subjects (Table II), all seven patients with Cushing's syndrome were observed to excrete excessive amounts of 11-oxygenated 17ketosteroids. The proportion of 11-oxygenated 17-ketosteroids relative to total ketosteroids was also greater than normal. 11 Beta-hydroxyandrosterone, 11 beta-hydroxyetiocholanolone, and 11-ketoetiocholanolone together comprised 40 to 66 per cent of the total as compared with 9 to 40 per cent in the normal individuals (Tables II and III). Of special interest was the relatively large amount of 11 beta-hydroxyandrosterone identified in the urine of five of the seven patients (all except Arp. and Par., Table III) (see Discussion). 2) In six of the seven patients (all except Fan.), the total quantity of 11 -deoxy 17 -ketosteroids was within normal limits (compare data of Tables II and III). A striking finding in five of the seven (all except Cor. and Bon.) was the alteration in the ratio of etiocholanolone to androsterone. In the normal subject, the ratio of the two steroids averages about 1 (Table II). The average etiocholanolone to androsterone ratio in these patients with Cushing's syndrome was 4.1 (Table III). 3 ) In only two of the seven patients with Cushing's syndrome was there a detectable quantity of the beta ketosteroids, isoandrosterone and dehydroisoandrosterone (Patients See. and Fan., Table III). Neither of these two subjects excreted an excessive proportion of beta ketosteroids, but Fan. showed a marked increase in the absolute quantity of dehydroisoandrosterone $(14.0 \mathrm{mg}$. per 24 hours as compared with $6.4 \mathrm{mg}$. per 24 hours, the extreme upper limit observed in the normal females).

Effects of corticotropin administration. Table IV shows the urinary excretion values for the 17-ketosteroids following corticotropin administration to Patients Bon. and Fan. A greater rise in 11-oxygenated than in 11-deoxy 17-ketosteroids was observed. The ratio of etiocholanolone to androsterone was not increased over the control value in either patient. Both of these findings are similar to those reported by Kappas, Dobriner 


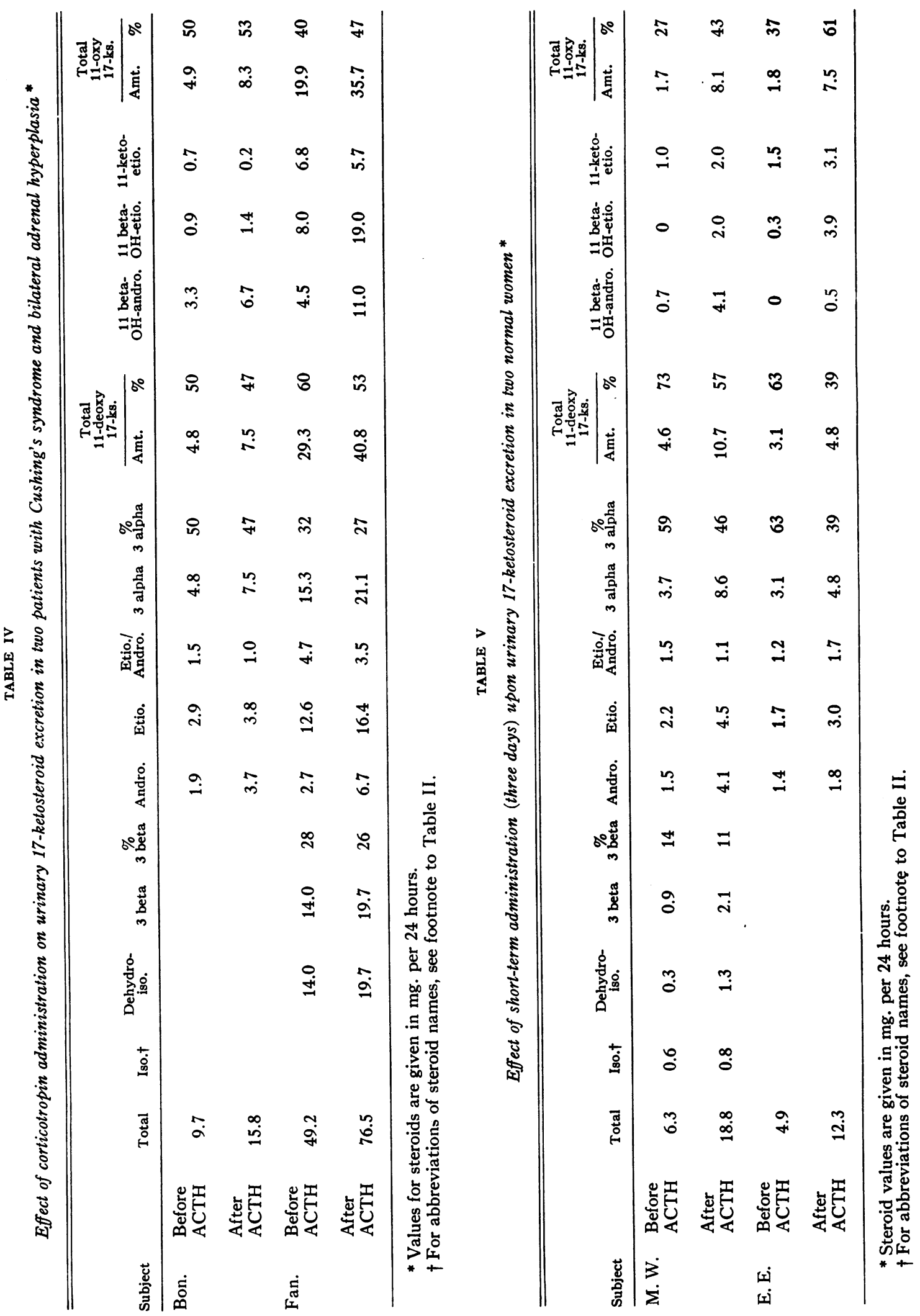


and Gallagher for normal subjects to whom ACTH was administered $(14,15)$.

\section{Effects of corticotropin in subjects without adrenal cortical disease}

Table V shows the excretion values for the 17ketosteroids before and during the intramuscular administration of ACTH to two normal women over a three day period. In both subjects, there was the expected increase in excretion of 11-oxygenated 17-ketosteroids, the increase being relatively greater than that observed for the 11-deoxy17-ketosteroids. In M.W., 11 beta-hydroxyandrosterone excretion increased more than did the excretion of 11 beta-hydroxyetiocholanolone or 11keto etiocholanolone. No significant change in the ratio of etiocholanolone to androsterone was observed in either subject over this short period of ACTH administration, a finding also reported by Kappas and Gallagher for normal women treated with ACTH (15).

The effects of long-term ACTH administration upon 17-ketosteroid excretion are presented in Table VI. Patient M.S. had an abnormal excretory pattern of 17 -ketosteroids with a relative increase in the quantity of 11-oxygenated 17-ketosteroids. Only a trace of androsterone could be detected, and $1.4 \mathrm{mg}$. of etiocholanolone was present. In E.U., the ratio of etiocholanolone to androsterone was approximately 10 (compare Table II, normal subjects). The quantity of the individual 11-oxygenated 17-ketosteroids could not be exactly determined since 11 beta-hydroxyandrosterone was not chromatographically separated from 11-ketoetiocholanolone.

\section{DISCUSSION}

The urinary 17-ketosteroid pattern observed in these patients with Cushing's syndrome and bilateral adrenal cortical hyperplasia is a characteristic one, and differs from the ketosteroid pattern found in normal subjects and from that reported in other types of adrenal cortical disease $(16,30,32)$. But the abnormal 17-ketosteroid pattern in Cushing's syndrome with adrenal hyperplasia derives its chief interest from its possible bearing upon the problem of deranged adrenal cortical secretion, and further, from its possible bearing upon the pathogenesis of the disorder. In the following discussion, it is assumed that the urinary steroid pattern is a more or less direct reflection of adrenal cortical secretion. The possibility cannot be excluded that some or all of the abnormalities observed might have been related to changes in the peripheral metabolism of adrenal steroids, changes which are peculiar to Cushing's syndrome. To date, no such metabolic errors in Cushing's syndrome have been demonstrated.

The increase in the urinary excretion of 11oxygenated 17-ketosteroids is not surprising and can be adequately accounted for by the increased amount of hydrocortisone which is presumably secreted by the adrenal cortex in Cushing's syndrome. The increase in hydrocortisone secretion appears to be amply documented by the findings of elevated plasma hydrocortisone levels (17-19) and increased urinary excretion of C21 metabolic products of hydrocortisone, tetrahydro $E$ and tetrahydro F (20). 11 Beta-hydroxyandrosterone, 11 beta-hydroxyetiocholanolone, and 11-ketoetiocholanolone have been shown to be the principal

TABLE VI

Urinary 17-ketosteroids after long-term corticotropin (two and three years) *

\begin{tabular}{|c|c|c|c|c|c|c|c|c|c|c|c|c|c|c|}
\hline \multirow[b]{2}{*}{ Subject } & \multirow[b]{2}{*}{ Total } & \multirow[b]{2}{*}{3 beta } & \multirow[b]{2}{*}{ Andro. $†$} & \multirow[b]{2}{*}{ Etio. } & \multirow{2}{*}{$\begin{array}{c}\text { Etio./ } \\
\text { Andro. }\end{array}$} & \multirow[b]{2}{*}{3 alpha } & \multirow{2}{*}{3 alpha } & \multicolumn{2}{|c|}{$\begin{array}{l}\text { Total } \\
\text { 11-deoxy } \\
\text { 17-ks. }\end{array}$} & \multirow{2}{*}{$\begin{array}{l}11 \beta-O H \\
\text { andro. }\end{array}$} & \multirow{2}{*}{$\begin{array}{c}11 \beta-O H \\
\text { etio. }\end{array}$} & \multirow{2}{*}{$\begin{array}{l}\text { 11-keto- } \\
\text { etio. }\end{array}$} & \multicolumn{2}{|c|}{$\begin{array}{c}\text { Total } \\
11-\text { oxy } \\
17-\mathrm{ks} .\end{array}$} \\
\hline & & & & & & & & Amt. & $\%$ & & & & Amt. & $\%$ \\
\hline $\begin{array}{l}\text { M.S. } \\
\text { E. U. }\end{array}$ & $\begin{array}{l}5.9 \\
9.4\end{array}$ & $\begin{array}{l}0 \\
0\end{array}$ & $\begin{array}{c}\mathrm{tr} \\
0.5\end{array}$ & $\begin{array}{l}1.4 \\
5.3\end{array}$ & $\begin{array}{l}>1.4 \\
10.6\end{array}$ & $\begin{array}{l}1.4 \\
5.8\end{array}$ & $\begin{array}{l}24 \\
62\end{array}$ & $\begin{array}{l}1.4 \\
5.8\end{array}$ & $\begin{array}{l}24 \\
62\end{array}$ & 1.3 & 2.0 & 1.2 & $\begin{array}{l}4.5 \\
3.6 \ddagger\end{array}$ & $\begin{array}{l}76 \\
38\end{array}$ \\
\hline
\end{tabular}

*Values for steroids are given in mg. per 24 hours.

$\dagger$ For abbreviations of steroid names, see footnote to Table II.

$\$ 11$-Ketoetiocholanolone and 11 beta-OH-androsterone were not chromatographically resolved. 
C19 excretory products of administered hydrocortisone $^{2}(22)$.

The relative proportions of the individual 11oxy 17 -ketosteroids one to another are not readily accounted for by an increased secretion of hydrocortisone alone. The infusion of 4-C ${ }^{14}$-labeled hydrocortisone in man has been reported to result in the urinary excretion of labeled 11 beta-hydroxyandrosterone, 11 beta-hydroxyetiocholanolone, and 11-ketoetiocholanolone in the ratio 2:9:9 (21). The ratio of the three steroids observed in certain of the patients with Cushing's syndrome is very different from this (Table III, Patients Cor., See., Bon. and Gol., in whom these ratios were approximately $8: 2: 1,13: 1: 1,7: 1: 3$ and $5: 4: 2$ ). It is possible that a precursor other than hydrocortisone may contribute in an important way to the excretion of 11-oxygenated 17-ketosteroids in Cushing's syndrome. One such precursor might conceivably be $\Delta^{4}$-androstene- 11 beta-ol-3,17-dione, a normal constituent of adrenal vein blood, which has been shown to be converted to 11 betahydroxyandrosterone, 11 beta-hydroxyetiocholanolone, and 11-ketoetiocholanolone in the ratio $12: 1: 2(23)$.

The ratio of etiocholanolone to androsterone in five of the seven patients with Cushing's syndrome is above the extreme upper limit found in normal individuals in the present investigation (compare Tables II and III) and in earlier studies by Kappas, Dobriner and Gallagher ${ }^{3}(14,15)$. The average ratio of etiocholanolone to androsterone in normal subjects is close to unity (Table II) (14, 15). The identity of the adrenal cortical precursor of etiocholanolone and androsterone in normal subjects is not known, but the $1: 1$ urinary ratio of the two steroids has led to speculation concerning

2 Gallagher was unable to show that hydrocortisone administration gives rise to an appreciable quantity of urinary 11 -keto-androsterone (21). In the present study, it was also impossible to identify this steroid conclusively in any patient. With the methods used, trace amounts (less than $100 \mu \mathrm{g}$. per 24 hours) could have gone undetected.

${ }^{3}$ The high average ratio of etiocholanolone $(4: 1)$ cannot be explained on the basis of excessive adrenal secretion of hydrocortisone. Studies of urinary 17-ketosteroids after cortisone or hydrocortisone administration have not shown increased urinary excretion of any 11deoxy 17-ketosteroid $(14,22)$. In fact, there has been to date no demonstration of the in vivo removal of the oxygen function at $\mathrm{C} 11$ from the steroid nucleus (24). their origin. For example, it has been postulated $(14,15,25-27)$ that the precursor is a C19 11-deoxy steroid because, in a limited number of studies, it has been shown that the administration of certain of these steroids (testosterone, dehydroisoandrosterone, $\Delta^{4}$-androstene-3,17-dione) results in the urinary excretion of etiocholanolone and androsterone in roughly equal proportions [etiocholanolone: androsterone 1.5:1 (26), average etiocholanolone: androsterone ratio in several experiments $1.7: 1$ (27)]. Thus, although a $\mathrm{C} 19$ precursor may contribute to the quantity of etiocholanolone in the patients with Cushing's syndrome, a major portion of this steroid may well be derived from a C21 precursor. One precursor which might be supposed to account for the altered ratio of etiocholanolone to androsterone is the C21 11-deoxy 17-hydroxysteroid, Reichstein's Substance S. Administration of this steroid to human subjects has been found to result in the urinary excretion of greater quantities of etiocholanolone than of androsterone $(28,29)$. Another 11-deoxy 17-hydroxy steroid of the C21 series, 17 alpha-hydroxyprogesterone, administration of which has been shown to give rise to a high etiocholanolone: androsterone ratio, does not appear to be a likely precursor because its principal excretory products, pregnanetriol and 17 alpha-hydroxypregnanolone, are not increased in this form of Cushing's syndrome (30). In a few of these patients, pregnanetriol was found in amounts not exceeding normal. In any event, it would seem that a search for the 11-deoxy 17-ketosteroid precursors in this disorder should be directed toward $\mathrm{C} 21$ rather than $\mathrm{C} 19$ compounds (27).

Dehydroisoandrosterone was not isolated in excess from any patient with Cushing's syndrome except Fan. (Table III). This observation is in accord with the results of most studies of urinary 17-ketosteroids in Cushing's syndrome (31). It has been found by most investigators that excessive quantities of dehydroisoandrosterone are not present in the urine of patients with adrenal hyperplasia, but that large amounts of this steroid may be present in the urine of patients with adrenal cortical carcinoma (31). Recent studies suggest that abnormally large quantities of dehydroisoandrosterone are by no means invariably found in adrenal cortical carcinoma (32). Be- 
cause the precursor (or precursors) of dehydroisoandrosterone is unknown at this time, the true significance of this steroid as a urinary excretory product is difficult to assess $(33,34)$.

Since all of the clinical features of Cushing's syndrome can be reproduced by the administration of $\mathrm{ACTH}$, it was considered important to determine whether or not this pituitary hormone was capable of bringing about the changes in urinary 17 -ketosteroid excretion which appeared to be characteristic of the naturally-occurring disorder. The present studies are in agreement with previous work in that they show a greater relative rise in 11-oxy than in 11-deoxy 17-ketosteroid excretion after the short-term administration of ACTH (15). The failure to bring about an increase in the ratio of etiocholanolone to androsterone with a short course of ACTH is also in agreement with earlier work $(14,15)$. In contrast, the administration of corticotropin to two patients for two and three years was associated with an increase in this ratio, which, in Patient E.U. (Table VI), was quantitatively comparable to the change in etiocholanolone: androsterone ratio observed in the patients with adrenal cortical hyperplasia (Table III). On the basis of the limited evidence now available, it seems improbable that chronic disease alone (e.g., rheumatoid arthritis as in E.U.) satisfactorily accounts for the abnormality in 11-deoxy 17-ketosteroid excretion. Birke has reported that the ratio of etiocholanolone to androsterone in a group of patients with long-standing rheumatoid arthritis was essentially normal (35).

Concerning possible alterations in 17-ketosteroid precursors secreted by the ACTH-stimulated adrenal cortex, the observations of Touchstone, Bulaschenko, Richardson and Dohan may be pertinent (20). These workers have reported the isolation of a metabolic product of Substance S, tetrahydro $S$, from the urine of ACTH-treated subjects. Although corticotropin-treated normals and patients with Cushing's syndrome associated with bilateral adrenal hyperplasia have high etiocholanolone: androsterone ratios (present study), one hesitates to draw an analogy between the two groups. This is because tetrahydro $\mathrm{S}$ has to date been definitely identified only in the urine of patients with Cushing's syndrome associated with adrenal cortical carcinoma $(20,36)$, and only tentatively identified in urine of patients with adrenal hyperplasia (20). It is also necessary to exercise caution in equating bilateral adrenal cortical hyperplasia with ACTH-treated normal subjects, since several investigators have failed to demonstrate increased quantities of circulating ACTH in patients with Cushing's syndrome $(37,38)$, although abnormal corticotropic activity of unknown origin has been reported (39).

It is conceivable that administered ACTH, given over long periods, may be capable of causing profound qualitative changes in corticosteroid biosynthesis, perhaps by affecting the relative activities of the various steroid hydroxylases in the adrenal cortex [e.g., 11 beta-hydroxylase (40)]. An example of such a change may perhaps be found in the observation of Kass, Hechter, Macchi and $\mathrm{Mou}$ that prolonged $\mathrm{ACTH}$ administration altered the ratio of hydrocortisone to corticosterone in the adrenal vein blood of rabbits (41). A possible relationship between the corticotropin-stimulated adrenal cortex and naturally-occurring adrenal cortical hyperplasia remains a subject for future investigation.

\section{SUMMARY}

In Cushing's syndrome associated with bilateral adrenal cortical hyperplasia, urinary 17 -ketosteroids were fractionated by means of column chromatography and identified by infrared spectroscopy. The excretory pattern of 17 -ketosteroids in seven patients with this disorder exhibited the following characteristics:

1. An absolute and relative increase in the 11oxygenated 17-ketosteroids.

2. An absolute increase in the quantity of 11 beta-OH-androsterone which was out of proportion to the value that would be expected on the basis of excessive adrenal secretion of hydrocortisone alone.

3. An average ratio of etiocholanolone to androsterone approximately four times greater than that observed in normal subjects. Total values of androsterone were normal in all seven; total values of etiocholanolone were above the upper limit of normal in four.

4. The absence of detectable quantities of dehydroisoandrosterone in five of the seven patients; 
the presence of an abnormally large quantity of dehydroisoandrosterone in one of the seven.

Prolonged administration of corticotropin to two patients without adrenal cortical disease was associated with a high ratio of etiocholanolone to androsterone.

\section{REFERENCES}

1. Forbes, A. P., and Albright, F. A comparison of the 17-ketosteroid excretion in Cushing's syndrome associated with adrenal tumor and with adrenal hyperplasia. J. clin. Endocr. 1951, 11, 926.

2. Devis, R. Méthodes chimiques et applications cliniques du fractionnement des stéroides urinaires. Ann. Endocr. (Paris) 1951, 12, 451.

3. Bauer, J. K. Die Ausscheidung von neutral C-17 ketosteroiden und Corticoiden bei Hyperplasie und Tumor der Nebennierenrinde. Dtsch. med. Wschr. 1951, 76, 1528.

4. Benard, H., and Horn, A. Les Dosages Hormonaux dans les syndromes d'hyperfonctionnement du cortex surrénal. Ann. Endocr. (Paris) 1952, 13, 286.

5. Gray, C. Etude de l'excrétion des stéroïdes corticosurrenaux et de leurs métabolites a l'état pathologique. Ann. Endocr. (Paris) 1953, 14, 869.

6. Pond, M. H. 17-Ketosteroid fractionation studies by a micro-chromatographic technique in endocrine disorders. J. Endocr. 1954, 10, 202.

7. Kovacic, N., Matovinovic, J., and Prosenjak, M. Quantitative differences in urinary 17-ketosteroid excretion in patients with Cushing's syndrome. Acta endocr. (Kbh.) 1957, 24, 393.

8. Holtorff, A. F., and Koch, F. C. The colorimetric estimation of 17-ketosteroids and their application to urine extracts. J. biol. Chem. 1940, 135, 377.

9. Lieberman, S., Mond, B., and Smyles, E. Hydrolysis of urinary ketosteroid conjugates. Recent Progr. Hormone Res. 1954, 9, 113.

10. Lakshmanan, T. K., and Lieberman, S. An improved method of gradient elution chromatography and its application to the separation of urinary ketosteroids. Arch. Biochem. Biophys. 1954, 53, 258.

11. Wilson, $\mathrm{H}$. Chromogenic values of ketosteroids in the Zimmermann reaction. Fed. Proc. 1950, 9, 246.

12. Bitman, J., Rosselet, J. P., Reddy, A. deM., and Lieberman, S. A spectrophotometric method for the analysis of binary mixtures of urinary steroids. J. biol. Chem. 1957, 225, 39.

13. Lieberman, S., and Dobriner, K. Steroid excretion in health and disease. I. Chemical aspects. Recent Progr. Hormone Res. 1948, 3, 71.

14. Kappas, A., Dobriner, K., and Gallagher, T. F. Studies in steroid metabolism. XXVII. A comparison of the steroid response to ACTH and cortisone in normal young men. J. clin. Invest. 1955, 34, 1559.
15. Kappas, A., and Gallagher, T. F. Studies in steroid metabolism. XXVIII. The $\alpha$-ketosteroid pattern in normal females and the response to ACTH. J. clin. Invest. 1955, 34, 1566.

16. Gallagher, T. F., Kappas, A., Hellman, L., Lipsett, M. B., Pearson, O. H., and West, C. D. Adrenocortical hyperfunction in "iodiopathic" hirsutism and the Stein-Leventhal syndrome. J. clin. Invest. 1958, 37, 794.

17. Wallace, E. Z., Christy, N. P., and Jailer, J. W. Clinical application of the simplified Silber-Porter method for determining plasma 17-hydroxy-corticosteroids. J. clin. Endocr. 1955, 15, 1073.

18. Perkoff, G., Sandberg, A. A., Nelson, D. H., and Tyler, F. H. Clinical usefulness of determination of circulating 17-hydroxycorticosteroid levels. Arch. intern. Med. 1954, 93, 1.

19. Lindsay, A. E., Migeon, C. J., Nugent, C. A., and Brown, $H$. The diagnostic value of plasma and urinary 17-hydroxycorticosteroid determinations in Cushing's syndrome. Amer. J. Med. 1956, 20, 15.

20. Touchstone, J. C., Bulaschenko, H., Richardson, E. M., and Dohan, F. C. Excretion of pregnane-3 $\alpha, 17 \alpha$, 21-triol-20-one (tetrahydro $S$ ) in normal and pathologic urine. J. clin. Endocr. 1957, 17, 250.

21. Gallagher, T. F. On alterations in adrenal function, especially with adrenocortical carcinoma. Cancer Res. 1957, 17, 520.

22. Burstein, S., Savard, K., and Dorfman, R. I. The in vivo metabolism of hydrocortisone. Endocrinology 1953, 53, 88.

23. Bradlow, H. L., and Gallagher, T. F. Metabolism of $11 \beta$-hydroxy- $\Delta^{4}$-androstene-3,17-dione in man. $\mathrm{J}$. biol. Chem. 1957, 229, 505.

24. Lieberman, S., and Teich, S. Recent trends in the biochemistry of the steroid hormones. Pharmacol. Rev. 1953, 5, 285.

25. Dorfman, R. I., and Ungar, F. Metabolism of Steroid Hormones. Minneapolis, Burgess Publishing Co., 1953.

26. Fukushima, D. K., Bradlow, H. L., Dobriner, K., and Gallagher, T. F. The fate of testosterone infused intravenously in man. J. biol. Chem. 1954, 206, 863.

27. Dorfman, R. I. Neutral steroid hormone metabolites. Recent Progr. Hormone Res. 1954, 9, 5.

28. Birke, G. The effect of Reichstein's substance $S$ on the excretion of 17-ketosteroids. Acta endocrinol. (Kbh.) 1954, 15, 17.

29. Birke, G., and Plantin, L. O. A steroid metabolic study on adrenalectomized patients after administration of compounds $\mathrm{E}$ and $\mathrm{F}$ and Reichstein's substance S. Acta endocrinol. (Kbh.) 1954, 15, 61.

30. Jailer, J. W., Gold, J. J., Vande Wiele, R., and Lieberman, S. 17 $\alpha$-Hydroxyprogesterone and 21-desoxyhydrocortisone; their metabolism and possible role in congenital adrenal virilism. J. clin. Invest. 1955, 34, 1639. 
31. Mason, H. L., and Engstrom, W. W. The 17-ketosteroids: Their origin, determination and significance. Physiol. Rev. 1950, 30, 321.

32. Vande Wiele, R., Lieberman, S., Christy, N. P., and Jailer, J. W. Studies in Cushing's syndrome. IV. The excretion of urinary 17-ketosteroids in adrenal cortical tumors. Proc. Soc. exp. Biol. (N. Y.) In press.

33. Ronzoni, E. The excretion of dehydroisoandrosterone during adrenal stimulation with adrenocorticotropic hormone. J. clin. Endocr. 1952, 12, 527.

34. Lieberman, S., and Teich, S. Metabolic precursors of urinary dehydroisoandrosterone. J. clin. Endocr. 1953, 13, 1140.

35. Birke, G. The 17-ketosteroid excretion in rheumatoid arthritis. Acta med. scand. 1954, Suppl. 291, 83.

36. Rosselet, J. P., Overland, L., Jailer, J. W., and Lieberman, S. Die Isolierung von $3 \alpha, 17 \alpha, 21-$ Trioxypregnanon-(20) (THS) aus menschlichem Harm. Helv. chim. Acta 1954, 37, 1933.

37. Taylor, A. B., Albert, A., and Sprague, R. G. Adrenotrophic activity of human blood. Endocrinology 1949, 45, 335.
38. Paris, J., Upson, M., Jr., Sprague, R. G., Salassa, R. M., and Albert, A. Corticotropic activity of human blood. J. clin. Endocr. 1954, 14, 597.

39. Jailer, J. W., Longson, D., and Christy, N. P. Studies in Cushing's syndrome. II. Adrenal weightmaintaining activity in the plasma of patients with Cushing's syndrome. J. clin. Invest. 1957, 36, 1608.

40. Grant, J. K., Symington, T., and Duguid, W. P. Effect of adrenocorticotropic therapy on the in vitro $11 \beta$-hydroxylation of deoxycorticosterone by human adrenal homogenates. J. clin. Endocr. 1957, 17, 933.

41. Kass, E. H., Hechter, O., Macchi, I. A., and Mou, T. W. Changes in patterns of secretion of corticosteroids in rabbits after prolonged treatment with ACTH. Proc. Soc. exp. Biol. (N. Y.) 1954, 85, 583.

42. Silber, R. H., and Porter, C. C. The determination of 17,21-dihydroxy-20-ketosteroids in urine and plasma. J. biol. Chem. 1954, 210, 923.

43. Peterson, R. E., Wyngaarden, J. B., Guerra, S. L., Brodie, B. B., and Bunim, J. J. The physiological disposition and metabolic fate of hydrocortisone in man. J. clin. Invest. 1955, 34, 1779. 